\title{
20 AÑOS DE INTERSECCIONES EN ANTROPOLOGÍA
}

Escribo estas palabras desde mi rol actual de editora responsable de Intersecciones en Antropología $(I e A)$, para compartir con ustedes principalmente mi sentir transitando esta experiencia en los últimos años. No es mi intención hacer una síntesis de la historia de leA, sino darle reconocimiento al trabajo editorial, a aquella dedicada y ardua labor invisible que permite la publicación de un número y la permanente actualización de esta revista.

Hoy leA existe gracias al primer paso del proceso editorial, cuando se gestó la idea de crearla, que implicó impulsos, esfuerzos y acuerdos entre los varios actores que participaron. Esa creación no hubiera sido posible sin el acompañamiento institucional de la Facultad de Ciencias Sociales (FACSO) de la Universidad Nacional del Centro de la Provincia de Buenos Aires (UNICEN), cuyo apoyo constante a largo del tiempo ha permitido mantener hasta la actualidad esta revista científica dedicada a la arqueología. Imagino que esa etapa inicial seguramente fue una experiencia enriquecedora e imborrable para quienes la llevaron adelante.

Esa comunión de esfuerzos y compromisos continuó a lo largo de 20 años, en los cuales fueron cambiando los integrantes, pero se mantuvo el principio rector de calidad y transparencia en el proceso editorial. leA es una publicación científica de prestigio en Argentina y en Sudamérica en el campo de la arqueología, y durante muchos años también en el de la antropología social.

¿Cómo se logró y se mantuvo en el tiempo ese prestigio? Por la calidad en el contenido científico publicado, por el cumplimiento de plazos respondiendo a las necesidades de autores, sistema científico e índices de calidad editorial. ¿Cómo se consiguieron esos requisitos y objetivos particulares de leA? Por la confianza depositada en esta revista por los autores, por la labor responsable y desinteresada de los evaluadores y por el compromiso y dedicación de quienes han integrado e integran hoy el Comité Editor.

En leA siempre hemos apuntado a la conformación de un Comité Editor que compartiera los objetivos planteados por la revista: calidad científica, transparencia en el proceso de evaluación, responsabilidad y respeto para con los tiempos de los autores y plazos editoriales, y compromiso para alcanzar un producto final que enriquezca la arqueología argentina y sudamericana. Me parece importante destacar que los editores formamos parte del sistema de investigación científico y, por tanto, entregamos parte de nuestro tiempo (de investigación, personal, de docencia, etc.) para llevar adelante esta publicación, manteniendo los estándares alcanzados y proponiéndonos nuevos objetivos que hacen a la calidad que deseamos tenga la revista. La composición diversa y la interacción de los editores, con distintos lugares de trabajo, especializados en temáticas arqueológicas diversas y, fundamentalmente, con un juicio crítico propio en línea con los objetivos de leA, es el principal motor de una producción y publicación de trabajos científicos con un fuerte compromiso con la ética y la ciencia.

Quiero destacar lo importante que es para nosotros en leA la búsqueda y selección de revisores pertinentes, con experticia en la temática de cada trabajo y con compromiso en la valoración crítica solicitada. Su labor es clave para cumplir con los objetivos mencionados, así como lo es la de los autores que envían sus contribuciones en las que plasman en un texto los resultados y alcances de sus estudios e incorporan así conocimiento particular a la arqueología en distintas escalas espaciales y temporales. Como autores, conocemos el gran esfuerzo que requiere cumplir con nuestros objetivos personales de investigación, que se suman a otros en distintas esferas y escalas (e.g., tesis, becas, sistema científico, revistas en las que pretendemos publicar, instituciones en las que trabajamos).

Intersecciones en Antropología 21(2), julio-diciembre: 117-118. 2020. ISSN-e 1850-373X 
Este año 2020 leA cumple 20 años, y particularmente me ha tocado encabezar, en su Comité Editor, la puesta en práctica de un nuevo modo de publicar, cumpliendo con los estándares en constante actualización. Este proceso se venía gestionando desde años previos y tiene que ver con la línea editorial de la revista, que siempre ha apuntado hacia el conocimiento abierto, gratuito y hacia la transparencia del proceso editorial. En estos últimos años las revistas científicas en Latinoamérica están trabajando para alcanzar esos estándares, cumpliendo con los requerimientos de los distintos índices nacionales e internacionales. Estos objetivos conllevan un gran esfuerzo, voluntad y compromiso de todo el equipo editorial de le $A$ para alcanzar gradualmente los distintos requisitos que se necesitan y que revalorizan la revista al permitir la amplia distribución de su contenido en el ámbito científico y académico. Este logro beneficia a autores, instituciones editoras, revistas y a la comunidad toda en general, ya que hacia allí deberían y pretenden Ilegar los saberes generados desde la ciencia; a la sociedad de la que formamos parte autores, revisores y editores.

En lo personal, es un placer para mí ocupar este rol y trabajar para que le $A$ siga creciendo con los actuales editores asociados María Clara Álvarez, Carlos Angiorama, Karen Borrazzo, Ramiro Barberena, Adolfo Gil, Agustina Massigoge, Luciano Prates y Atilio F. Zangrando, con quienes trabajamos desde el compromiso y la colaboración (tres de ellos participaron durante muchos años, estuvieron desde que asumí este rol y recientemente se han retirado, por tanto son parte de los logros). María Gutiérrez, quien durante gran parte de estos 20 años dirigió la revista, nos sigue acompañando desde su rol actual como parte de las autoridades de la FACSO. Sin este trabajo en equipo los logros no hubieran Ilegado, sin el apoyo de la FACSO (UNICEN) durante las distintas gestiones no se publicaría le $A$, ya que tenemos gastos elevados de producción. En este sentido, una de las metas del actual equipo editorial es publicar con el menor costo posible para la institución que nos financia, y hacia allí estamos encaminados. Esta tarea insume tiempo, ya que implica aprender a manejar nuevas herramientas informáticas y técnicas. La publicación científica no comercial tiene su "precio".

Autores, evaluadores y editores somos los que conformamos leA. La investigación que hacemos como autores, el trabajo que realizamos como editores, y la evaluación que llevamos a cabo como revisores portan nuestras subjetividades teóricas, contextuales, circunstanciales, y las propias de una disciplina social. Somos individuos que interactúan en diferentes roles, que muchas veces se van alternando, y esto trae aparejadas particularidades, subjetividades, humanidades diferentes que se alían en la producción de conocimiento científico diverso, abierto, perfectible, y por tanto, enriquecedor y estimulante.

En este aniversario tan significativo y particular deseamos agradecer a los autores por seguir confiando en nuestra revista para dar a conocer sus investigaciones y a los evaluadores por colaborar con nosotros para cumplir nuestros objetivos de calidad y transparencia. Deseamos que la arqueología pueda seguir contribuyendo a las ciencias sociales en nuestro país, y en particular continúe generando conocimiento sobre ese pasado que nos identifica y nos une.

Mariela E. González Editora Responsable Intersecciones en Antropología 